\title{
Perpendekan Jalur Kritis Dengan Metode Fast Track (Overlap Method)
}

\author{
Sofyan Bachmid ${ }^{1}$, Watono ${ }^{2}$, St. Fatmah Arsal $^{3}$, Wahyudin ${ }^{4}$, Rahimul Yaqin Nur ${ }^{5}$ \\ 1,23,4,5 Teknik Sipil, Universitas Muslim Indonesia, Makassar, Indonesia \\ Email: ${ }^{1}$ sofyanbacmid@ymail.com, ${ }^{2}$ watono.watono@umi.ac.id, ${ }^{3}$ fathma.arsal@umi.ac.id, ${ }^{4}$ wahyudin5049@gmail.com, ${ }^{5}$ rahimul90@gmail.com
}

\begin{abstract}
Abstrak
Suatu proyek konstruksi dikerjakan dengan perencanaan yang matang agar proyek selesai sesuai dengan jangka waktu yang ditentukan. Pada umumnya, penjadwalan proyek menggunakan estimasi

Kata Kunci

Penjadwalan Proyek; Jalur kritis;

Fast

Tracking

(overlap

Method)
\end{abstract}

\begin{abstract}
A construction project is done with careful planning so that the project is completed in accordance with the specified time period. In general, project scheduling uses definite duration estimates. But there are many uncertainty factors so that the duration of each activity cannot be determined with

Keywords

Project scheduling; Critical path; Fast tracking (Overlap Method)
\end{abstract}

\section{PENDAHULUAN}

\subsection{Latar belakang}

Proyek adalah suatu rangkaian kegiatan yang dikerjakan dalam waktu terbatas. menggunakan sumber daya tertentu dengan harapan untuk mempe roleh hasil yang terbaik pada waktu yang akan datang. Sumber daya merupakan factor penentu dalam keberhasilan suatu proyek kontruksi. Sumber daya yang berpengaruh dalam proyek terdiri dari man, materials, machine, money dan method (Jusmidah, 2016). Proyek konstruksi adalah suatu kegiatan yang memiliki jangka waktu dalam penyelesainnya. Suatu proyek konstruksi dikerjakan dengan perencanaan yang matang agar proyek selesai sesuai dengan jangka waktu yang ditentukan(Sulistiono, 2016). Manajemen proyek merupakan strategi yang perlu dilakukan dalam mencapai efisiensi dan efektifitas suatu perusahaan (Arianie \& Puspitasari, 2017). keberhasilan suatu proyek konstruksi tidak terlepas dari 
pengambilan keputusan berdasarkan analisa dan tindakan koreksi terhadap berbagai factor risiko dari akibat kendala kendala yang dihadapi selama pelaksanaan proyek (Ismael, 2013).

Perencanaan merupakan bagian terpenting untuk mencapai keberhasilan proyek konstruksi (Tanjung, 2017). Perencanaan, penjadwalan dan pengendalian adalah langkah penting untuk dilakukan agar tujuan proyek dapat tercapai (Sudarsana 2018). Pengaruh perencanaan terhadap proyek konstruksi akan berdampak pada pendapatan dalam proyek itu sendiri. Salah satu bentuk dari perencanaan suatu proyek adalah penjadwalan proyek. Penjadwalan proyek merupakan salah satu elemen hasil perencanaan, yang dapat memberikan informasi tentang jadwal rencana dan kemajuan proyek dalam hal kinerja sumber daya berupa biaya, tenaga kerja, peralatan dan material serta rencana durasi proyek dengan progress waktu untuk penyelesaian proyek.

Proyek konstruksi adalah suatu kegiatan yang memiliki jangka waktu dalam penyelesainnya. Suatu proyek konstruksidikerjakan dengan perencanaan yang matang agar proyek selesai sesuai dengan jangka waktu yang ditentukan. Pada umumnya, penjadwalan proyek menggunakan estimasi durasi yang pasti. Namun banyak faktor ketidakpastian (uncertainty) sehingga durasi masing-masing kegiatan tidak dapat ditentukan dengan pasti. Faktor penyebab ketidakpastian durasi tersebut diantaranya adalah produktivitas pekerja, faktor cuaca, persediaan alat, bahan dan lain-lain.

Pada metode jaringan kerja dikenal adanya jalur kritis, yaitu jalur yang memiliki rangkaian komponenkomponen kegiatan, dengan total jumlah waktu terlama dan menunjukkan kurun waktu penyelesaian proyek yang tercepat. Jadi, jalur kritis terdiri dari rangkaian kegiatan kritis, dimulai dari kegiatan pertama sampai pada kegiatan terakhir proyek (Soeharto, 1995).

Jalur kritis penting artinya bagi para pelaksana proyek, karena pada jalur ini terletak kegiatan-kegiatan yang pelaksanaannya harus selesai tepat waktu. Jika terjadi keterlambatan, maka akan menyebabkan keterlambatan proyek keseluruhan. Tujuan penelitian ini adalah untuk Mengetahui perpendekan waktu kritis pada pekerjaan Proyek Pembangunan Student Center Fakultas Kedokteran Universitas Hasanuddin setelah dihitung dengan metodeOverlap atau fast tracking method.

\section{METODE PENELITIAN}

Adapun metode yang digunakan padaProyek Pembangunan Student Center Fakultas Kedokteran Universitas Hasanuddin dengan menggunakan metode Fast Tracking Method (overlap).

Adapun data dan lokasi perencanaan sebagai berikut: (a) Nama bangunan: Gedung Studen Center Fakultas Universitas Hasanuddin; (b) Fungsi: Gedung; (c) Lokasi bangunan : Jl. Perintis Kemerdekaan, Makassar; (d) Anggaran:Rp.5.996.863.000,00,-; (e) Jumlah lantai : 3 Lantai + Atap; (f) Luas Bangunan : $4.944 \mathrm{~m}^{2}$; (g) Masa Pelaksanaan: 118 hari kerjadengan waktu 8 jam perhari dan 7 hari per minggu (senin-minggu)

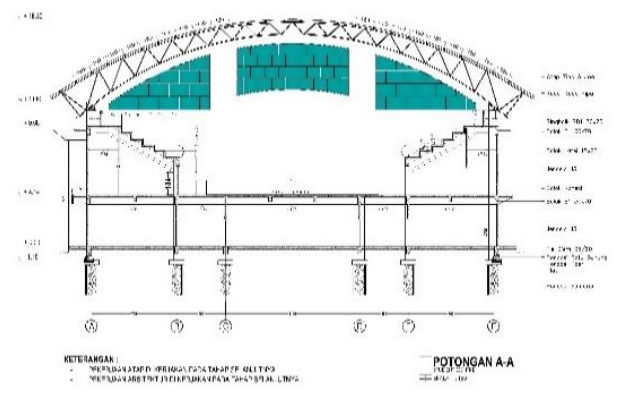

Gambar 1. Potongan gambar perencanaan

Pembangunan gedung Student center Fakultas kedokteran Universitas Hasanuddin Makassar Terletak di sebelah Utara Fakultas Pertanian dan Sebelah selatan Gedung Pasca Serjana yang berlokasi di Jl. Perintis kemerdekaan Makassar 


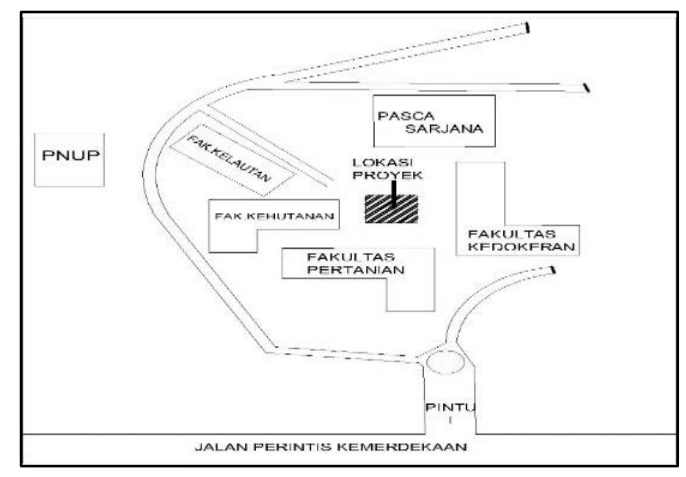

Gambar 2. Site Plan Lokasi Proyek

\section{Langkah - langkah Penjadwalan proyek}

Analisa proyek pembangunan Gedung Student Center Fakultas Kedokteran UNHAS Makassar menggunakan metode fast track (overlap) . Dengan langkah-langkah sebagai berikut :

a) Terlebih dahulu menetukansimbol kegiatan pekerjaan pada proyek pembangunan Gedung Student Center Fakultas Kedokteran UNHAS Makassar.

Tabel 1. Simbol kegiatan

\begin{tabular}{|c|c|c|}
\hline No & Uraian Pekerjaan & Simbol \\
\hline \multirow[t]{23}{*}{$\mathbf{I}$} & Pekerjaan Tanah dan Pondasi & \\
\hline & 1. Pek. Pondasi Sumuran, Kedalaman $-3,00$ (Dari Peil $\pm 0,00$ Tanah Existing & \\
\hline & - Pek. Galian Tanah Pondasi Sumuran & A \\
\hline & - Pek. Sirtu Alas Pondasi Sumuran & $\mathrm{B}$ \\
\hline & - Pek. Urungan Tanah Pondasi Sumuran (Sisi Luar Sumuran ) & $\mathrm{C}$ \\
\hline & - Pek. Pondasi Sumuran, Dia. $80 \mathrm{~cm}$, Kedalaman 1,00 m & $\mathrm{D}$ \\
\hline & - Pek. Beton Siklop Pondasi Sumuran & $\mathrm{E}$ \\
\hline & (60\% Beton 1Pc : $2 \mathrm{~Pb}: 3 \mathrm{Kr}$ Dan 40\% Batu Kali/Belah) & \\
\hline & 2. Pek. Galian Pondasi Poer & $\mathrm{F}$ \\
\hline & 3. Pek. Galian Pondasi Batu & $\mathrm{G}$ \\
\hline & 4. Lantai Kerja Pondasi Poer Tebal $5 \mathrm{~cm}$ & $\mathrm{H}$ \\
\hline & 5. Pek. Pasir Urung Dibawah Pondasi Batu & 1 \\
\hline & 6. Pek. Pondasi Batu Kosong & $\mathrm{J}$ \\
\hline & 7. Pek. Pondasi Batu, Camp. $1 \mathrm{pc}: 5 \mathrm{ps}$ & $\mathrm{K}$ \\
\hline & 8. Pek. Urungan Kembali Galian Pondasi & $\mathrm{L}$ \\
\hline & 9. Pek. Pondasi Poer Type P1, Uk $125 \times 110 \mathrm{~cm}$ & \\
\hline & - Bekisting 2x Pakai & $\mathrm{M}$ \\
\hline & - Besi Beton & $\mathrm{N}$ \\
\hline & - Beton $(\mathrm{K} 300) \mathrm{fc}=26,4 \mathrm{Mpa}, \mathrm{slump}(12 \pm 2) \mathrm{cm}, \mathrm{w} / \mathrm{c}=0,52$ & $\mathrm{O}$ \\
\hline & 10. Pek. Pondasi Poer Type P2, Uk $125 \times 125 \mathrm{~cm}$ & \\
\hline & - Bekisting 2x Pakai & $\mathrm{P}$ \\
\hline & - Besi Beton & Q \\
\hline & - Beton $(\mathrm{K} 300) \mathrm{fc}=26,4 \mathrm{Mpa}, \operatorname{slump}(12 \pm 2) \mathrm{cm}, \mathrm{w} / \mathrm{c}=0,52$ & $\mathrm{R}$ \\
\hline
\end{tabular}




\begin{tabular}{|c|c|c|}
\hline & 11. Pek. Pondasi Poer Type P3, Uk $100 \times 233 \mathrm{~cm}$ & \\
\hline & - Bekisting 2x Pakai & $\mathrm{S}$ \\
\hline & - Besi Beton & $\mathrm{T}$ \\
\hline & - Beton $(\mathrm{K} 300) \mathrm{fc}=26,4 \mathrm{Mpa}$, slump $(12 \pm 2) \mathrm{cm}, \mathrm{w} / \mathrm{c}=0,52$ & $\mathrm{U}$ \\
\hline & 12. Pek. Stek Poer/Kolom Pedestal K1, Uk. $50 \times 80 \mathrm{~cm}$ & \\
\hline & - Bekisting 2x Pakai & $\mathrm{V}$ \\
\hline & - Besi Beton & W \\
\hline & - Beton $(\mathrm{K} 300) \mathrm{fc}=26,4 \mathrm{Mpa}, \operatorname{slump}(12 \pm 2) \mathrm{cm}, \mathrm{w} / \mathrm{c}=0,52$ & $\mathrm{x}$ \\
\hline & 13. Pek. Stek Poer/Kolom Pedestal K2, Uk. $50 \times 60 \mathrm{~cm}$ & \\
\hline & - Bekisting 2x Pakai & $\mathrm{Y}$ \\
\hline & - Besi Beton & Z \\
\hline & - Beton $(\mathrm{K} 300) \mathrm{fc}=26,4 \mathrm{Mpa}$, slump $(12 \pm 2) \mathrm{cm}, \mathrm{w} / \mathrm{c}=0,52$ & $\mathrm{AA}$ \\
\hline & 14. Pek. Stek poer/Kolom Pedestal K3, Uk. $50 \times 50 \mathrm{~cm}$ & \\
\hline & - Bekisting 2x Pakai & $A B$ \\
\hline & - Besi Beton & $\mathrm{AC}$ \\
\hline & - Beton $(\mathrm{K} 300) \mathrm{fc}=26,4 \mathrm{Mpa}, \operatorname{slump}(12 \pm 2) \mathrm{cm}, \mathrm{w} / \mathrm{c}=0,52$ & $\mathrm{AD}$ \\
\hline II & PEKERJAAN STRUKTUR & \\
\hline A & Pekerjaan Tie Beam/Sloef & \\
\hline & 1. Pek. Sloof TB1, Uk. $35 \times 60 \mathrm{~cm}$ & \\
\hline & - Bekistin 2x Pake & $\mathrm{AE}$ \\
\hline & - Besi Beton & AF \\
\hline & - Beton $(\mathrm{K} 300) \mathrm{fc}=26,4 \mathrm{Mpa}$, slump $(12 \pm 2) \mathrm{cm}, \mathrm{w} / \mathrm{c}=0,52$ & AG \\
\hline & 2. Pek. Sloof TB2, Uk. $40 \times 80 \mathrm{~cm}$ & \\
\hline & - Bekistin 2x Pake & $\mathrm{AH}$ \\
\hline & - Besi Beton & $\mathrm{Al}$ \\
\hline & - Beton $(\mathrm{K} 300) \mathrm{fc}=26,4 \mathrm{Mpa}$, slump $(12 \pm 2) \mathrm{cm}, \mathrm{w} / \mathrm{c}=0,52$ & AJ \\
\hline & 3. Pek. Sloof SL1, Uk. $25 \times 30 \mathrm{~cm}$ & \\
\hline & - Bekistin 2xPake & AK \\
\hline & - Besi Beton & $\mathrm{AL}$ \\
\hline & - Beton $(\mathrm{K} 300) \mathrm{fc}=26,4 \mathrm{Mpa}$, slump $(12 \pm 2) \mathrm{cm}, \mathrm{w} / \mathrm{c}=0,52$ & AM \\
\hline B & Pekerjaan Kolom Struktur & \\
\hline B1 & Pekerjaan Kolom Lt. 1 & \\
\hline & 1. Pek. Kolom K1. Uk. $50 \times 80 \mathrm{~cm}$ & \\
\hline & - Bekistin 2x Pake & AN \\
\hline & - Besi Beton & $\mathrm{AO}$ \\
\hline & - Beton $(\mathrm{K} 300) \mathrm{fc}=26,4 \mathrm{Mpa}$, slump $(12 \pm 2) \mathrm{cm}, \mathrm{w} / \mathrm{c}=0,52$ & AP \\
\hline & 2. Pek. Kolom K1. Uk. $50 \times 60 \mathrm{~cm} 6$ buah & \\
\hline & - Bekistin 2x Pake & $\mathrm{AQ}$ \\
\hline & - Besi Beton & AR \\
\hline & - Beton $(\mathrm{K} 300) \mathrm{fc}=26,4 \mathrm{Mpa}, \mathrm{slump}(12 \pm 2) \mathrm{cm}, \mathrm{w} / \mathrm{c}=0,52$ & AS \\
\hline & 3. Pek. Kolom K3, Uk.50 ×50 cm & \\
\hline & - Bekisting 2x Pakai & AT \\
\hline & - Besi Beton & $\mathrm{AU}$ \\
\hline & - Beton $(\mathrm{K} 300) \mathrm{fc}=26,4 \mathrm{Mpa}$, slump $(12 \pm 2) \mathrm{cm}, \mathrm{w} / \mathrm{c}=0,52$ & $\mathrm{AV}$ \\
\hline B2 & Pekerjaan Kolom Lt. 2 & \\
\hline & 1. Pek. Kolom K1. Uk. $50 \times 80 \mathrm{~cm}$ & \\
\hline & - Bekistin 2x Pake & AW \\
\hline & - Besi Beton & $\mathrm{AX}$ \\
\hline & - Beton $(\mathrm{K} 300) \mathrm{fc}=26,4 \mathrm{Mpa}$, slump $(12 \pm 2) \mathrm{cm}, \mathrm{w} / \mathrm{c}=0,52$ & AY \\
\hline & 2. Pek. Kolom K2, Uk $50 \times 60 \mathrm{~cm}$ & \\
\hline & - Bekistin 2x Pake & $\mathrm{AZ}$ \\
\hline & - Besi Beton & BA \\
\hline & - Beton $(\mathrm{K} 300) \mathrm{fc}=26,4 \mathrm{Mpa}$, slump $(12 \pm 2) \mathrm{cm}, \mathrm{w} / \mathrm{c}=0,52$ & $\mathrm{BB}$ \\
\hline & 3. Pek. Kolom K3, Uk $50 \times 50 \mathrm{~cm}$ & \\
\hline & - Bekisting 2x Pakai & BC \\
\hline & - Besi Beton & $\mathrm{BD}$ \\
\hline & - Beton $(\mathrm{K} 300) \mathrm{fc}=26,4 \mathrm{Mpa}$, slump $(12 \pm 2) \mathrm{cm}, \mathrm{w} / \mathrm{c}=0,52$ & $\mathrm{BE}$ \\
\hline
\end{tabular}




\begin{tabular}{|c|c|c|}
\hline B3 & Pekerjaan Kolom TRIBUN Lt. III & \\
\hline & 1. Pek. Kolom K1, Uk. $50 \times 80 \mathrm{~cm}$, dan Pek. Kolom K2, Uk $50 \times 60 \mathrm{~cm}$ & \\
\hline & - Bekisting 2xpakai & $\mathrm{BF}$ \\
\hline & - Besi Kolom & BG \\
\hline & - Beton $(\mathrm{K} 300) \mathrm{fc}=26,4 \mathrm{Mpa}, \operatorname{slump}(12 \pm 2) \mathrm{cm}, \mathrm{w} / \mathrm{c}=0,52$ & $\mathrm{BH}$ \\
\hline $\mathbf{C}$ & Pekerjaan Balok dan Rangka & \\
\hline \multirow[t]{17}{*}{ C1 } & Pekerjaan Balok Lt.2 & \\
\hline & 1. Pek. Balok B1, Uk. $30 \times 70 \mathrm{~cm}$ & \\
\hline & - Bekisting 2xpakai & $\mathrm{BI}$ \\
\hline & - Besi Kolom & BJ \\
\hline & - Beton $(\mathrm{K} 300) \mathrm{fc}=26,4 \mathrm{Mpa}, \operatorname{slump}(12 \pm 2) \mathrm{cm}, \mathrm{w} / \mathrm{c}=0,52$ & BK \\
\hline & 2. Pek. Balok B2, Uk. $30 \times 60 \mathrm{~cm}$, & \\
\hline & - Bekisting 2xpakai & $\mathrm{BL}$ \\
\hline & - Besi Kolom & BM \\
\hline & - Beton $(\mathrm{K} 300) \mathrm{fc}=26,4 \mathrm{Mpa}, \operatorname{slump}(12 \pm 2) \mathrm{cm}, \mathrm{w} / \mathrm{c}=0,52$ & $\mathrm{BN}$ \\
\hline & 3. Pek. Balok B3, Uk. $40 \times 90 \mathrm{~cm}$ & \\
\hline & - Bekisting 2xpakai & $\mathrm{BO}$ \\
\hline & - Besi Kolom & $\mathrm{BP}$ \\
\hline & - Beton $(\mathrm{K} 300) \mathrm{fc}=26,4 \mathrm{Mpa}$, slump $(12 \pm 2) \mathrm{cm}, \mathrm{w} / \mathrm{c}=0,52$ & $\mathrm{BQ}$ \\
\hline & 4. Pek. Balok B4, Uk. $25 \times 50 \mathrm{~cm}$ & \\
\hline & - Bekisting 2x pakai & BR \\
\hline & - Besi Kolom & BS \\
\hline & - Beton $(\mathrm{K} 300) \mathrm{fc}=26,4 \mathrm{Mpa}, \mathrm{slump}(12 \pm 2) \mathrm{cm}, \mathrm{w} / \mathrm{c}=0,52$ & BT \\
\hline \multirow[t]{13}{*}{$\mathbf{C 2}$} & Pekerjaan Balok Lt.3 & \\
\hline & 1. Pek. Balok B1, Uk. $30 \times 70 \mathrm{~cm}$ & \\
\hline & - Bekisting 2xpakai & $\mathrm{BU}$ \\
\hline & - Besi Kolom & BV \\
\hline & - Beton $(\mathrm{K} 300) \mathrm{fc}=26,4 \mathrm{Mpa}, \mathrm{slump}(12 \pm 2) \mathrm{cm}, \mathrm{w} / \mathrm{c}=0,52$ & BW \\
\hline & 2. Pek. Balok B2, Uk. $30 \times 60 \mathrm{~cm}$, & \\
\hline & - Bekisting 2xpakai & $\mathrm{BX}$ \\
\hline & - Besi Kolom & BY \\
\hline & - Beton $(\mathrm{K} 300) \mathrm{fc}=26,4 \mathrm{Mpa}, \mathrm{slump}(12 \pm 2) \mathrm{cm}, \mathrm{w} / \mathrm{c}=0,52$ & $\mathrm{BZ}$ \\
\hline & 3. Pek. Balok B3, Uk. $40 \times 90 \mathrm{~cm}$ & \\
\hline & - Bekisting 2x pakai & CA \\
\hline & - Besi Kolom & $\mathrm{CB}$ \\
\hline & - Beton $(\mathrm{K} 300) \mathrm{fc}=26,4 \mathrm{Mpa}$, slump $(12 \pm 2) \mathrm{cm}, \mathrm{w} / \mathrm{c}=0,52$ & $\mathrm{CC}$ \\
\hline \multirow[t]{13}{*}{ C3 } & Pekerjaan Ringbalk & \\
\hline & 1. Pek. Ringbalk RB1, Uk. $30 \times 75 \mathrm{~cm}$ & \\
\hline & - Bekisting 2xpakai & CD \\
\hline & - Besi Kolom & $\mathrm{CE}$ \\
\hline & - Beton $(\mathrm{K} 300) \mathrm{fc}=26,4 \mathrm{Mpa}, \mathrm{slump}(12 \pm 2) \mathrm{cm}, \mathrm{w} / \mathrm{c}=0,52$ & $\mathrm{CF}$ \\
\hline & 2. Pek. Ringbalk RB2, Uk. $30 \times 60 \mathrm{~cm}$ & \\
\hline & - Bekisting 2xpakai & CG \\
\hline & - Besi Kolom & $\mathrm{CH}$ \\
\hline & - Beton $(\mathrm{K} 300) \mathrm{fc}=26,4 \mathrm{Mpa}, \operatorname{slump}(12 \pm 2) \mathrm{cm}, \mathrm{w} / \mathrm{c}=0,52$ & $\mathrm{Cl}$ \\
\hline & 3. Pek. Ringbalk RB3, Uk. $40 \times 90 \mathrm{~cm}$ & \\
\hline & - Bekisting 2x pakai & CJ \\
\hline & - Besi Kolom & CK \\
\hline & - Beton $(\mathrm{K} 300) \mathrm{fc}=26,4 \mathrm{Mpa}, \mathrm{slump}(12 \pm 2) \mathrm{cm}, \mathrm{w} / \mathrm{c}=0,52$ & $\mathrm{CL}$ \\
\hline \multirow[t]{5}{*}{ C4 } & Pekerjaan Plat, Tribun dan Tangga & \\
\hline & 1. Pek. Plat Lantaill & \\
\hline & - Structural Floor Decking & $\mathrm{CM}$ \\
\hline & - Wiremesh M10 & $\mathrm{CN}$ \\
\hline & - Beton $(\mathrm{K} 300) \mathrm{fc}=26,4 \mathrm{Mpa}, \mathrm{s}$ lump $(12 \pm 2) \mathrm{cm}, \mathrm{w} / \mathrm{c}=0,52$ & $\mathrm{CO}$ \\
\hline
\end{tabular}


Perpendekan Jalur Kritis Dengan Metode Fast Track (Overlap Method)

Sofyan Bachmid, Watono, St. Fatmah Arsal, Wahyudin, Rahimul Yaqin Nur

\begin{tabular}{|c|c|}
\hline 3. Pek. Plat Tribun & \\
\hline - Bekisting 2x Pakai & $C P$ \\
\hline -Besi Beton & $\mathrm{CQ}$ \\
\hline - Beton (K300) fc=26,4 Mpa, slump (12 \pm 2$) \mathrm{cm}, \mathrm{w} / \mathrm{c}=0,52$ & $\mathrm{CR}$ \\
\hline 4. Pek. Plat Entrance Elev +5.32 & \\
\hline - Bekisting 2xPakai & CS \\
\hline - Besi Beton & CT \\
\hline - Beton $(\mathrm{K} 300) \mathrm{fc}=26,4 \mathrm{Mpa}, \mathrm{slump}(12 \pm 2) \mathrm{cm}, \mathrm{w} / \mathrm{c}=0,52$ & $\mathrm{CU}$ \\
\hline 5. Pek. Plat Elev+ 4.14 & \\
\hline - Bekisting 2x Pakai & $\mathrm{CV}$ \\
\hline - Besi Beton & $\mathrm{CW}$ \\
\hline - Beton (K300) fc=26,4 Mpa, slump $(12 \pm 2) \mathrm{cm}, \mathrm{w} / \mathrm{c}=0,52$ & $\mathrm{CX}$ \\
\hline 6. Pek. Plat Elev+9.4 & \\
\hline - Bekisting 2x Pakai & $\mathrm{CY}$ \\
\hline - Besi Beton & $\mathrm{CZ}$ \\
\hline - Beton $(\mathrm{K} 300) \mathrm{fc}=26,4 \mathrm{Mpa}, \mathrm{s} / \mathrm{ump}(12 \pm 2) \mathrm{cm}, \mathrm{w} / \mathrm{c}=0,52$ & DA \\
\hline 7. Pek. Tangga Beton I LT.1 - LT.2 & \\
\hline - Bekisting 2x Pakai & DB \\
\hline - Besi Beton & $\mathrm{DC}$ \\
\hline - Beton K225 ( $\mathrm{fc}=19.3 \mathrm{Mpa}(\mathrm{K} 225), \mathrm{Slump}(12 \pm 2) \mathrm{cm}, \mathrm{w} / \mathrm{c}=0.58)$ & $\mathrm{DD}$ \\
\hline 8. Pek. Tangga Beton II LT.2 - LT.3 & \\
\hline - Bekisting 2xPakai & $\mathrm{DE}$ \\
\hline - Besi Beton & DF \\
\hline - Beton (K300) fc=26,4 Mpa, slump (12 \pm 2$) \mathrm{cm}, \mathrm{w} / \mathrm{c}=0,52$ & DG \\
\hline
\end{tabular}

b) Setelah menetukan simbol kegiatan pekerjaan pada proyek pembangunan Gedung Student Center Fakultas Kedokteran UNHAS Makassar, kemudian menyusun jaringan logika ketergantungan antar kegiatan. Kegiatan antar kegiatan adalah hubungan urutan pelaksanaan kegiatan satu dengan lainnya sehingga terangkai dalam paket pekerjaan proyek.

Tabel 2. Logika Ketergantungan

\begin{tabular}{|c|c|c|c|c|c|c|c|c|c|}
\hline \multirow{2}{*}{ NO } & \multirow{2}{*}{ Kode Aktifitas } & \multirow{2}{*}{ Durasi } & \multicolumn{2}{|c|}{ Aktifitas } & \multirow{2}{*}{$\frac{31}{32}$} & \multirow{2}{*}{$\frac{\mathrm{AE}}{\mathrm{AF}}$} & \multirow{2}{*}{$\begin{array}{l}4 \\
3\end{array}$} & \multirow{2}{*}{$\begin{array}{l}\mathrm{U}, \mathrm{T} \\
\mathrm{U}, \mathrm{T}\end{array}$} & \multirow{2}{*}{$\frac{\mathrm{AG}}{\mathrm{AH}}$} \\
\hline & & & Sebelum & Sesudah & & & & & \\
\hline 1 & $\mathrm{~A}$ & 3 & - & $\mathrm{B}$ & 33 & $\mathrm{AG}$ & 4 & $\mathrm{AE}$ & $\mathrm{AH}$ \\
\hline 2 & $\mathrm{~B}$ & 1 & $\mathrm{~A}$ & $\mathrm{C}$ & 34 & $\mathrm{AH}$ & 4 & AG,AF & $\mathrm{AI}$ \\
\hline 3 & $\mathrm{C}$ & 1 & $\mathrm{~B}$ & $\mathrm{D}, \mathrm{E}$ & 35 & $\mathrm{AI}$ & 3 & $\mathrm{AH}$ & $\mathrm{AJ}$ \\
\hline 4 & $\mathrm{D}$ & 6 & $\mathrm{C}$ & $\mathrm{I}$ & 36 & $\mathrm{AJ}$ & 4 & $\mathrm{AI}$ & $\mathrm{AN}, \mathrm{AO}$ \\
\hline 5 & $\mathrm{E}$ & 6 & $\mathrm{C}$ & $\mathrm{J}$ & 37 & $\mathrm{AK}$ & 2 & AA & $\mathrm{AL}$ \\
\hline 6 & $\mathrm{~F}$ & 3 & - & $\mathrm{N}, \mathrm{M}$ & 38 & $\mathrm{AL}$ & 2 & $\mathrm{AK}, \mathrm{AD}$ & $\mathrm{AM}$ \\
\hline$\frac{7}{8}$ & $\mathrm{G}$ & $\frac{4}{1}$ & $\frac{-}{G}$ & $\frac{\mathrm{H}}{\mathrm{NM}}$ & 39 & $\mathrm{AM}$ & 1 & $\mathrm{AL}$ & AS \\
\hline$\frac{8}{9}$ & $\frac{\mathrm{H}}{\mathrm{I}}$ & $\frac{1}{1}$ & $\frac{G}{D}$ & $\frac{\mathrm{N}, \mathrm{M}}{\mathrm{J}}$ & 40 & AN & 4 & $\mathrm{AJ}$ & $\mathrm{AP}$ \\
\hline 10 & $\mathrm{~J}$ & 3 & $\mathrm{I}, \mathrm{E}$ & $\mathrm{K}$ & 41 & $\mathrm{AO}$ & 3 & $\mathrm{AJ}$ & $\mathrm{AR}, \mathrm{AQ}$ \\
\hline 11 & $\mathrm{~K}$ & 4 & $\mathrm{~J}$ & $\mathrm{~L}$ & 42 & $\mathrm{AP}$ & 3 & AN & $\mathrm{AQ}, \mathrm{AR}$ \\
\hline 12 & $\mathrm{~L}$ & 1 & $\mathrm{~K}$ & $\mathrm{~d} 1$ & 43 & $\mathrm{AQ}$ & 4 & $\mathrm{AP}, \mathrm{AO}$ & $\mathrm{AQ}, \mathrm{AR}$ \\
\hline 13 & $\mathrm{M}$ & 2 & $\mathrm{H}, \mathrm{F}$ & $\mathrm{O}$ & 44 & $\mathrm{AR}$ & 3 & $\mathrm{AP}, \mathrm{AO}$ & AT,AU,BJ,BI \\
\hline 14 & $\mathrm{~N}$ & 2 & $\mathrm{H}, \mathrm{F}$ & $\mathrm{P}, \mathrm{Q}$ & 45 & AS & 3 & $\mathrm{AQ}, \mathrm{AM}$ & AT,AU,BJ,BI \\
\hline 15 & 0 & 2 & $\mathrm{M}$ & $\mathrm{P}, \mathrm{O}$ & 46 & $\mathrm{AT}$ & 4 & AS,AR & $\mathrm{AV}$ \\
\hline 16 & $\mathrm{P}$ & 2 & $\mathrm{O}, \mathrm{N}$ & $\mathrm{R}$ & 47 & $\mathrm{AU}$ & 3 & AS,AR & $\mathrm{d} 2$ \\
\hline 17 & Q & 2 & $\mathrm{O}, \mathrm{N}$ & $\mathrm{S}, \mathrm{T}$ & 48 & $\mathrm{AV}$ & 3 & $\mathrm{AT}$ & $\mathrm{d} 2$ \\
\hline 18 & $\mathrm{R}$ & 2 & $\mathrm{P}$ & $\mathrm{S}, \mathrm{T}$ & 49 & AW & 4 & $\mathrm{CO}, \mathrm{CN}$ & $\mathrm{AY}$ \\
\hline 19 & $S$ & 2 & $\mathrm{R}, \mathrm{Q}$ & $\mathrm{U}$ & 50 & $\mathrm{AX}$ & 3 & $\mathrm{CO}, \mathrm{CN}$ & AZ,BA \\
\hline 20 & $\mathrm{~T}$ & 2 & $\mathrm{R}, \mathrm{Q}$ & $\mathrm{V}, \mathrm{WAE}, \mathrm{AF}$ & 51 & AY & 3 & $\mathrm{AW}$ & $\mathrm{AZ}, \mathrm{BA}$ \\
\hline 21 & $\mathrm{U}$ & 2 & $\mathrm{~S}$ & $\frac{\mathrm{V}, \mathrm{WAE}, \mathrm{AF}}{\mathrm{Y}}$ & 52 & $\mathrm{AZ}$ & 4 & $\mathrm{AY}, \mathrm{AX}$ & BB \\
\hline$\frac{22}{23}$ & $\frac{\mathrm{V}}{\mathrm{w}}$ & 2 & $\mathrm{U}, \mathrm{T}$ & $\frac{\mathrm{X}}{\mathrm{y}}$ & 53 & $\mathrm{BA}$ & 3 & $\mathrm{AY}, \mathrm{AX}$ & $\mathrm{BC}, \mathrm{BD}$ \\
\hline$\frac{23}{24}$ & $\frac{W}{X}$ & $\frac{2}{2}$ & $\frac{\mathrm{U}, \mathrm{T}}{\mathrm{V}, \mathrm{d} 1}$ & $\frac{\mathrm{Y}, \mathrm{AC}}{\mathrm{Y}, \mathrm{AC}}$ & 54 & $\mathrm{BB}$ & 3 & $\mathrm{AZ}$ & $\mathrm{BC}, \mathrm{BD}$ \\
\hline 25 & $\frac{A}{Y}$ & $\frac{2}{2}$ & X,W & $\frac{1, A C}{Z}$ & 55 & $\mathrm{BC}$ & 4 & $\mathrm{BB}, \mathrm{BA}$ & $\mathrm{BE}$ \\
\hline 26 & $\mathrm{Z}$ & 3 & $\mathrm{Y}$ & AA & 56 & $\mathrm{BD}$ & 3 & $\mathrm{BB}, \mathrm{BA}$ & $\mathrm{BF}, \mathrm{BG}$ \\
\hline 27 & AA & 4 & $\mathrm{Z}$ & $\mathrm{AK}$ & 57 & $\mathrm{BE}$ & 5 & $\mathrm{BC}$ & $\mathrm{BF}, \mathrm{BG}$ \\
\hline 28 & $\mathrm{AB}$ & 2 & $\mathrm{AC}$ & $\mathrm{AD}$ & 58 & $\mathrm{BF}$ & 3 & $\mathrm{BE}, \mathrm{BD}$ & $\mathrm{BH}$ \\
\hline 29 & $\mathrm{AC}$ & 3 & $\mathrm{X}, \mathrm{W}$ & $\mathrm{AB}$ & 59 & $\mathrm{BG}$ & 2 & $\mathrm{BE}, \mathrm{BD}$ & $\mathrm{d} 7$ \\
\hline 30 & $\mathrm{AD}$ & 4 & $\mathrm{AB}$ & $\mathrm{AL}$ & 60 & $\mathrm{BH}$ & 2 & $\mathrm{BF}$ & $\mathrm{CD}, \mathrm{CE}$ \\
\hline
\end{tabular}




\begin{tabular}{|c|c|c|c|c|}
\hline 61 & $\mathrm{BI}$ & 5 & $\mathrm{AS}, \mathrm{AR}$ & $\mathrm{BK}$ \\
\hline 62 & BJ & 4 & AS,AR & $\mathrm{BL}, \mathrm{BO}, \mathrm{BR}, \mathrm{BS}$ \\
\hline 63 & BK & 4 & BI & $\mathrm{BL}, \mathrm{BO}, \mathrm{BR}, \mathrm{BS}$ \\
\hline 64 & $\mathrm{BL}$ & 5 & $\mathrm{BK}, \mathrm{BJ}$ & $\mathrm{BN}$ \\
\hline 65 & $\mathrm{BM}$ & 4 & $\mathrm{BK}, \mathrm{BJ}$ & $\mathrm{CM}, \mathrm{CN}, \mathrm{CT}, \mathrm{CS}$ \\
\hline 66 & $\mathrm{BN}$ & 4 & $\mathrm{BL}, \mathrm{d} 2$ & $\mathrm{CM}, \mathrm{CN}, \mathrm{CT}, \mathrm{CS}$ \\
\hline 67 & BO & 2 & $\mathrm{BK}, \mathrm{BJ}$ & BP \\
\hline 68 & $\mathrm{BP}$ & 1 & BO & $\mathrm{BQ}$ \\
\hline 69 & $\mathrm{BQ}$ & 1 & $\mathrm{BP}$ & $\mathrm{d} 4$ \\
\hline 70 & BR & 3 & $\mathrm{BK}, \mathrm{BJ}$ & BT \\
\hline 71 & BS & 2 & $\mathrm{BK}, \mathrm{BJ}$ & d3 \\
\hline 72 & BT & 2 & $\mathrm{BR}$ & d3 \\
\hline 73 & $\mathrm{BU}$ & 5 & $\mathrm{DD}, \mathrm{DC}$ & BW \\
\hline 74 & BV & 4 & $\mathrm{DD}, \mathrm{DC}$ & $\mathrm{BX}, \mathrm{BY}, \mathrm{CA}, \mathrm{CB}, \mathrm{CM}, \mathrm{CN}$ \\
\hline 75 & BW & 4 & $\mathrm{BU}$ & $\mathrm{BX}, \mathrm{BY}, \mathrm{CA}, \mathrm{CB}, \mathrm{CM}, \mathrm{CN}$ \\
\hline 76 & $\mathrm{BX}$ & 5 & $\mathrm{BW}, \mathrm{BV}$ & $\mathrm{BZ}$ \\
\hline 77 & BY & 4 & $\mathrm{BW}, \mathrm{BV}$ & $\mathrm{d} 5$ \\
\hline 78 & $\mathrm{BX}$ & 4 & $\mathrm{BX}$ & $\mathrm{BZ}$ \\
\hline 79 & $\mathrm{CA}$ & 2 & $\mathrm{BW}, \mathrm{BV}$ & $\mathrm{CC}$ \\
\hline 80 & $\mathrm{CB}$ & 1 & $\mathrm{BW}, \mathrm{BF}$ & $\mathrm{d} 6$ \\
\hline 81 & $\mathrm{CC}$ & 1 & $\mathrm{CA}$ & $\mathrm{d} 6$ \\
\hline 82 & $\mathrm{CD}$ & 5 & $\mathrm{BH}, \mathrm{d} 7$ & $\mathrm{CF}$ \\
\hline 83 & CE & 4 & $\mathrm{BH}, \mathrm{d} 7$ & CG \\
\hline 84 & $\mathrm{CF}$ & 4 & $\mathrm{CD}$ & $\mathrm{CG}$ \\
\hline 85 & $\mathrm{CG}$ & 5 & CE,CF & $\mathrm{CI}$ \\
\hline 86 & $\mathrm{CH}$ & 3 & $\mathrm{CL}, \mathrm{d} 9$ & - \\
\hline
\end{tabular}

\begin{tabular}{|c|c|c|c|c|}
\hline 87 & $\mathrm{CI}$ & 3 & $\mathrm{CG}$ & - \\
\hline 88 & $\mathrm{CJ}$ & 3 & $\mathrm{DG}, \mathrm{d} 8$ & $\mathrm{CL}$ \\
\hline 89 & $\mathrm{CK}$ & 2 & $\mathrm{DG}, \mathrm{d} 8$ & $\mathrm{~d} 9$ \\
\hline 90 & $\mathrm{CL}$ & 6 & $\mathrm{CJ}$ & $\mathrm{CH}$ \\
\hline 91 & $\mathrm{CN}$ & 4 & $\mathrm{BN}, \mathrm{BM}, \mathrm{d} 4$ & $\mathrm{AW}, \mathrm{AX}$ \\
\hline 92 & $\mathrm{CM}$ & 3 & $\mathrm{BN}, \mathrm{BM}, \mathrm{d} 4$ & $\mathrm{CO}$ \\
\hline 93 & $\mathrm{CO}$ & 3 & $\mathrm{CM}$ & $\mathrm{AW}, \mathrm{AX}$ \\
\hline 94 & $\mathrm{CP}$ & 4 & $\mathrm{CO}, \mathrm{CN}$ & $\mathrm{CR}$ \\
\hline 95 & $\mathrm{CQ}$ & 3 & $\mathrm{CO}, \mathrm{CN}$ & $\mathrm{DE}$ \\
\hline 96 & $\mathrm{CR}$ & 3 & $\mathrm{CP}, \mathrm{d} 6$ & $\mathrm{DE}$ \\
\hline 97 & $\mathrm{CS}$ & 2 & $\mathrm{BM}, \mathrm{BN}, \mathrm{d} 4$ & $\mathrm{CU}$ \\
\hline 98 & $\mathrm{CT}$ & 1 & $\mathrm{BM}, \mathrm{BN}, \mathrm{d} 4$ & $\mathrm{DC}, \mathrm{DB}$ \\
\hline 99 & $\mathrm{CU}$ & 2 & $\mathrm{CS}$ & $\mathrm{DC}, \mathrm{DB}$ \\
\hline 100 & $\mathrm{CV}$ & 2 & $\mathrm{CO}, \mathrm{CN}$ & $\mathrm{CX}$ \\
\hline 101 & $\mathrm{CW}$ & 3 & $\mathrm{CO}, \mathrm{CN}$ & $\mathrm{DF}$ \\
\hline 102 & $\mathrm{CX}$ & 1 & $\mathrm{CV}$ & $\mathrm{DF}$ \\
\hline 103 & $\mathrm{CY}$ & 4 & $\mathrm{DG}, \mathrm{d} 8$ & $\mathrm{DA}$ \\
\hline 104 & $\mathrm{CZ}$ & 3 & $\mathrm{DG}, \mathrm{d} 8$ & $\mathrm{~d} 10$ \\
\hline 105 & $\mathrm{DA}$ & 3 & $\mathrm{CY}$ & $\mathrm{CH}$ \\
\hline 106 & $\mathrm{DB}$ & 3 & $\mathrm{CU}, \mathrm{CT}$ & $\mathrm{DD}$ \\
\hline 107 & $\mathrm{DC}$ & 3 & $\mathrm{CU}, \mathrm{CT}$ & $\mathrm{BV}, \mathrm{BU}$ \\
\hline 108 & $\mathrm{DD}$ & 3 & $\mathrm{DB}$ & $\mathrm{BV}, \mathrm{BU}$ \\
\hline 109 & $\mathrm{DE}$ & 3 & $\mathrm{CR}, \mathrm{CQ}$ & $\mathrm{DG}$ \\
\hline 110 & $\mathrm{DF}$ & 2 & $\mathrm{CX}, \mathrm{CW}$ & $\mathrm{d} 8$ \\
\hline 111 & $\mathrm{DG}$ & 2 & $\mathrm{DE}$ & $\mathrm{CJ}, \mathrm{CK}$ \\
\hline
\end{tabular}

c) Setelah analisa ketergantungan diuraikan pada tabel diatas maka selanjutnya dapat dibuat diagram Network Planning. Adanya network ini menjadikan sistem manajemen dapat menyusun perencanaan penyelesaian proyek dengan waktu dan biaya yang paling efisien. Di samping itu network juga dapat dipergunakan sebagai alat pengawasan yang cukup baik untuk menyelesaikan proyek tersebut. Diagram network merupakan kerangka penyelesaian proyek secara keseluruhan, ataupun masing-masing pekerjaan yang menjadi bagian dari pada penyelesaian proyek secara keseluruhan. Pada prinsipnya network digunakan untuk menentukan lintasan kritis pada proyek pembangunan Gedung Student Center Fakultas Kedokteran UNHAS Makassar
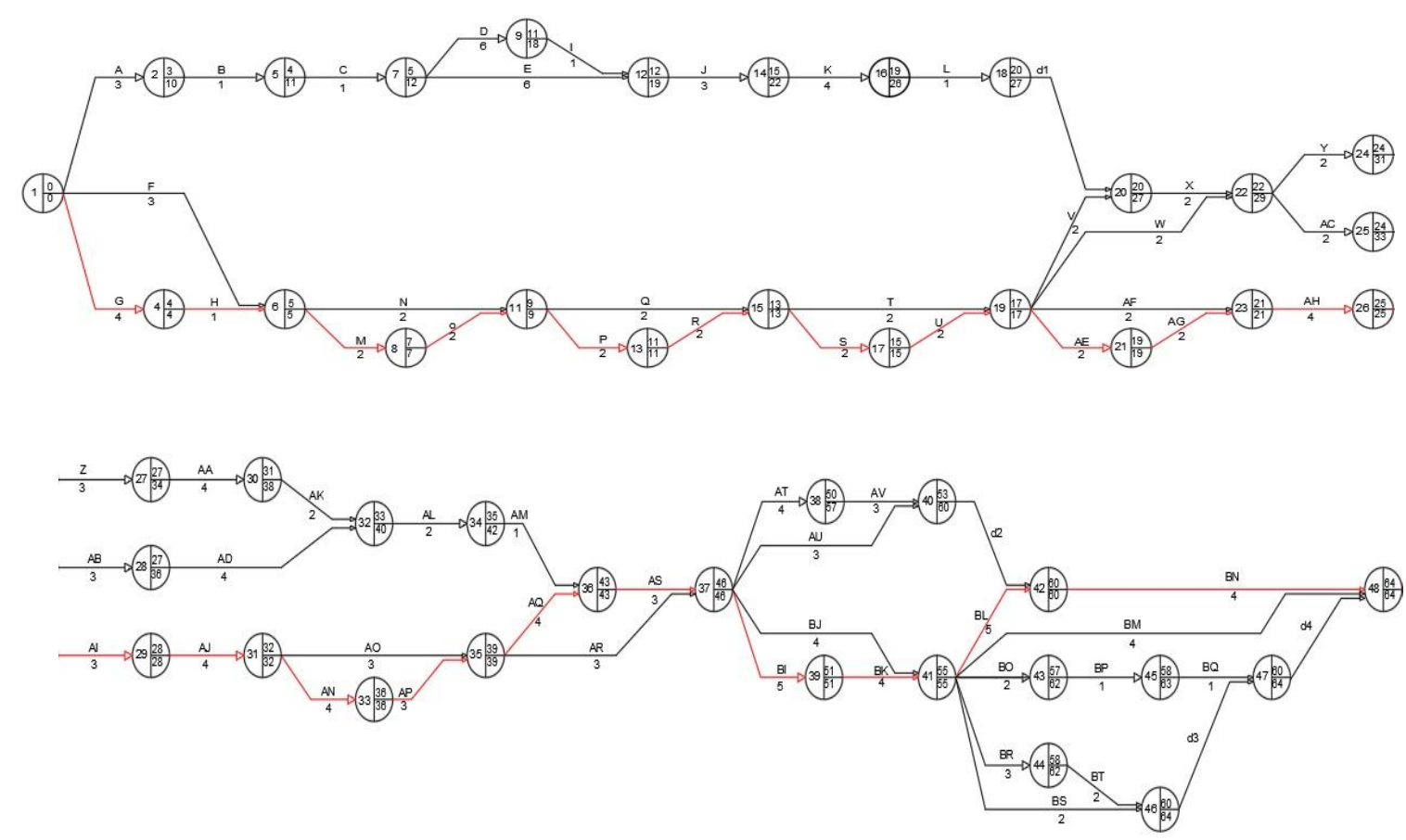

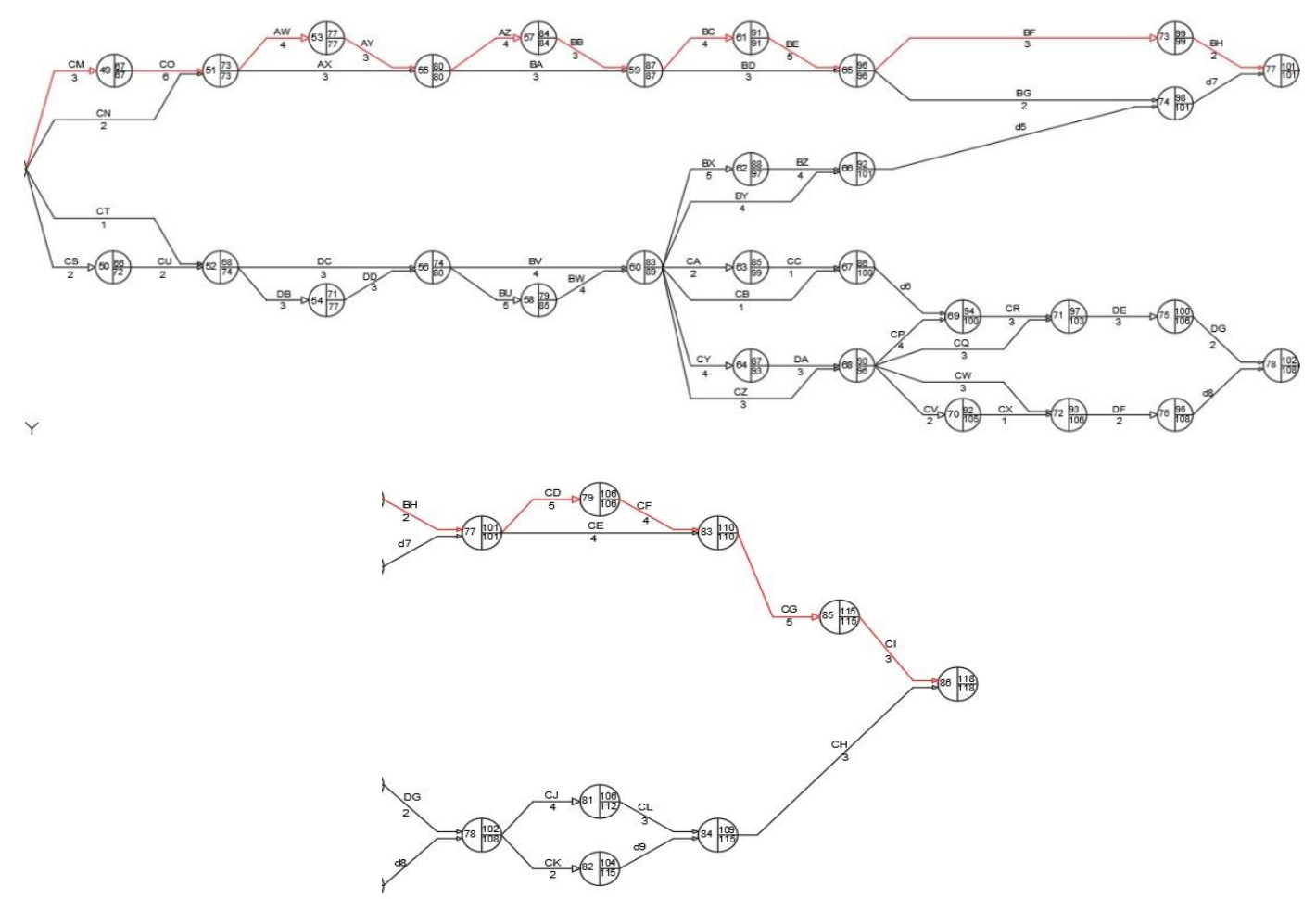

Gambar 3. Network Planning (CPM)

d) Analisa CPM (Critical Path Method) Metode ini digunakan untuk menentukan lintasan kritis pada proyek yang terdiri dari banyak aktivitas yang disusun dalam bentuk jaringan kerja. Setiap aktivitas diasumsikan mempunyai waktu permulaan, waktu penyelesaian. Setiap aktivitas dapat digambarkan sebagai aktivitas pada setiap node (aktivity on node).

Adapun untuk menghitung EST, EFT, LST, LFT, dan TF adalah sebagai berikut:

EST : Didapat dari durasi pekerjaan.

EFT : Didapat dari EST + Durasi pekerjaan

LST : Didapat dari EFT - Durasi

LFT : Didapat dari Durasi pekerjaan + LFT selanjutnya.

TF : Didapat dari LFT - Durasi - EST

FF : Didapat dari EFT - Durasi - EST

Tabel 3. Litasan kritis

\begin{tabular}{|c|c|c|c|c|c|c|c|c|}
\hline \multirow{3}{*}{ No } & \multirow{3}{*}{$\begin{array}{c}\text { Aktivitas } \\
\text { Kode }\end{array}$} & \multirow{3}{*}{$\begin{array}{c}\text { Durasi } \\
\text { Hari }\end{array}$} & \multicolumn{6}{|c|}{ ANALISA CPM } \\
\hline & & & \multicolumn{2}{|c|}{ Earliest } & \multicolumn{2}{|c|}{ Lastest } & \multicolumn{2}{|c|}{ Float } \\
\hline & & & EST & EFT & LST & LFT & TF & FF \\
\hline 1 & $\mathrm{G}$ & 4 & 0 & 4 & 0 & 4 & 0 & 0 \\
\hline 2 & $\mathrm{H}$ & 1 & 4 & 5 & 4 & 5 & 0 & 0 \\
\hline 3 & $\mathbf{M}$ & 2 & 5 & 7 & 5 & 7 & 0 & 0 \\
\hline 4 & $\mathrm{O}$ & 2 & 7 & 9 & 7 & 9 & 0 & 0 \\
\hline 5 & $\mathrm{P}$ & 2 & 9 & 11 & 9 & 11 & 0 & 0 \\
\hline 6 & $\mathrm{R}$ & 2 & 11 & 13 & 11 & 13 & 0 & 0 \\
\hline 7 & $\mathrm{~S}$ & 2 & 13 & 15 & 13 & 15 & 0 & 0 \\
\hline 8 & $\mathrm{U}$ & 2 & 15 & 17 & 15 & 17 & 0 & 0 \\
\hline 9 & $\mathrm{AE}$ & 2 & 17 & 19 & 17 & 19 & 0 & 0 \\
\hline 10 & $\mathrm{AG}$ & 2 & 19 & 21 & 19 & 21 & 0 & 0 \\
\hline 11 & $\mathrm{AH}$ & 4 & 21 & 25 & 21 & 25 & 0 & 0 \\
\hline 12 & AI & 3 & 25 & 28 & 25 & 28 & 0 & 0 \\
\hline 13 & $\mathrm{AJ}$ & 4 & 28 & 32 & 28 & 32 & 0 & 0 \\
\hline 14 & $\mathrm{AN}$ & 4 & 32 & 36 & 32 & 36 & 0 & 0 \\
\hline 15 & AP & 3 & 36 & 39 & 36 & 39 & 0 & 0 \\
\hline
\end{tabular}




\begin{tabular}{|l|c|c|c|c|c|c|c|c|}
\hline 16 & AQ & 4 & 39 & 43 & 39 & 43 & 0 & 0 \\
\hline 17 & AS & 3 & 43 & 46 & 43 & 46 & 0 & 0 \\
\hline 18 & BI & 5 & 46 & 51 & 46 & 51 & 0 & 0 \\
\hline 19 & BK & 4 & 51 & 55 & 51 & 55 & 0 & 0 \\
\hline 20 & BL & 5 & 55 & 60 & 55 & 60 & 0 & 0 \\
\hline 21 & BN & 4 & 60 & 64 & 60 & 64 & 0 & 0 \\
\hline 22 & CM & 3 & 64 & 67 & 64 & 67 & 0 & 0 \\
\hline 23 & CO & 6 & 67 & 73 & 67 & 73 & 0 & 0 \\
\hline 24 & AW & 4 & 73 & 77 & 73 & 77 & 0 & 0 \\
\hline 25 & AY & 3 & 77 & 80 & 77 & 80 & 0 & 0 \\
\hline 26 & AZ & 4 & 80 & 84 & 80 & 84 & 0 & 0 \\
\hline 27 & BB & 3 & 84 & 87 & 84 & 87 & 0 & 0 \\
\hline 28 & BC & 4 & 87 & 91 & 87 & 91 & 0 & 0 \\
\hline 29 & BE & 5 & 91 & 96 & 91 & 96 & 0 & 0 \\
\hline 30 & BF & 3 & 96 & 99 & 96 & 99 & 0 & 0 \\
\hline 31 & BH & 2 & 99 & 101 & 99 & 101 & 0 & 0 \\
\hline 32 & CD & 5 & 101 & 106 & 101 & 106 & 0 & 0 \\
\hline 33 & CF & 4 & 106 & 110 & 106 & 110 & 0 & 0 \\
\hline 34 & CG & 5 & 110 & 115 & 110 & 115 & 0 & 0 \\
\hline 35 & CI & 3 & 115 & 118 & 115 & 118 & 0 & 0 \\
\hline & Jumlah & 118 & & & & & 0 & 0 \\
\hline
\end{tabular}

e) Selanjutnya Membagi durasi aktivtas pada lintasan kritis menjadi sub aktivitas, pada pelaksanaan proyek pembangunan Gedung Student Center Fakultas Kedokteran UNHAS Makassar. Maka pada aktivitas kritis tersebut harus dipecah-pecah ke dalam bagian yang lebih kecil. Maksudnya agar kegiatan-kegiatan lain dapat dilaksanakan bertingkatan dengan bagian-bagian yang lebih kecil tadi. Dengan syarat aktivitas yang dipecah menjadi sub aktivitas jumlah durasinya harus sama dengan durusi aktivitas setelah menjadi sub aktivitas, dan aktivtas yang sama harus segaris. Adapun Network Planning untuk aktivtas pada lintasan kritis menjadi sub aktivitas pekerjaan Gedung student center fakultas kedokteran Universitas Hasanuddin.

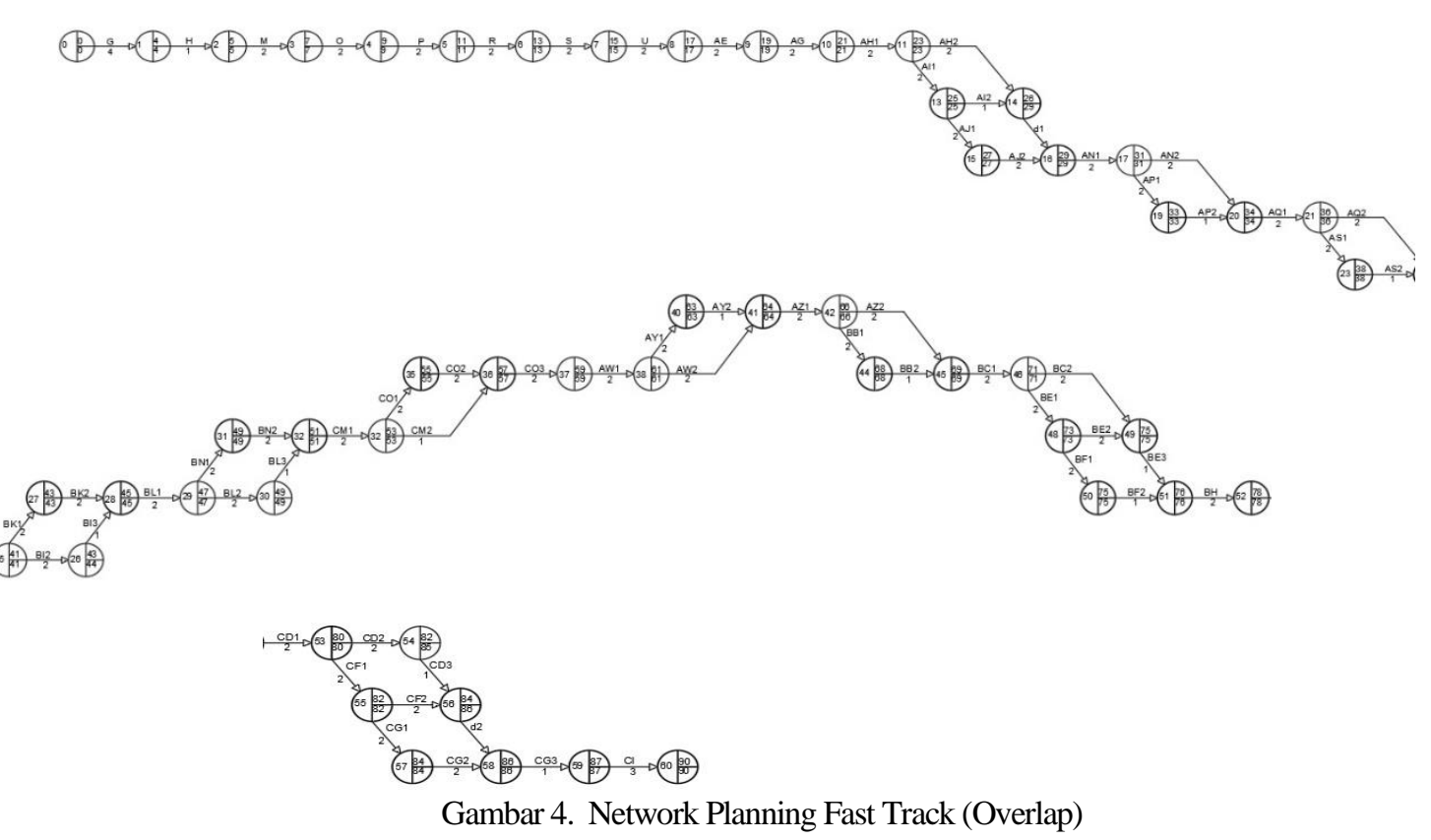

f) Kemudian menganalisa Fast Track untuk menghitung EST, EFT, LST, LFT, TF, dan FF adalah sebagai berikut :

EST : Durasi pekerjaan.

EFT : EST + Durasi pekerjaan

LST : EFT - Durasi

LFT : Durasi pekerjaan + LFT selanjutnya. 
Tabel 4. Informasi Fast Track

\begin{tabular}{|c|c|c|c|c|c|c|c|c|c|}
\hline \multirow{3}{*}{ No } & \multirow{3}{*}{$\begin{array}{l}\text { Aktivitas } \\
\text { (Kode) }\end{array}$} & \multirow{3}{*}{$\begin{array}{c}\text { Durasi } \\
\text { (Hari) }\end{array}$} & \multicolumn{6}{|c|}{ Analisa Fast Track } & \multirow{3}{*}{ Keterangan } \\
\hline & & & \multicolumn{2}{|c|}{ Earliest } & \multicolumn{2}{|c|}{ Lastest } & \multicolumn{2}{|c|}{ Float } & \\
\hline & & & EST & EFT & LST & LFT & TF & FF & \\
\hline 1 & G & 4 & 0 & 4 & 0 & 4 & 0 & 0 & Kritis \\
\hline 2 & $\mathrm{H}$ & 1 & 4 & 5 & 4 & 5 & 0 & 0 & Kritis \\
\hline 3 & $\mathrm{M}$ & 2 & 5 & 7 & 5 & 7 & 0 & 0 & Kritis \\
\hline 4 & $\mathrm{O}$ & 2 & 7 & 9 & 7 & 9 & 0 & 0 & Kritis \\
\hline 5 & $\mathrm{P}$ & 2 & 9 & 11 & 9 & 11 & 0 & 0 & Kritis \\
\hline 6 & $\mathrm{R}$ & 2 & 11 & 13 & 11 & 13 & 0 & 0 & Kritis \\
\hline 7 & $\mathrm{~S}$ & 2 & 13 & 15 & 13 & 15 & 0 & 0 & Kritis \\
\hline 8 & $\mathrm{U}$ & 2 & 15 & 17 & 15 & 17 & 0 & 0 & Kritis \\
\hline 9 & $\mathrm{AE}$ & 2 & 17 & 19 & 17 & 19 & 0 & 0 & Kritis \\
\hline 10 & $\mathrm{AG}$ & 2 & 19 & 21 & 19 & 21 & 0 & 0 & Kritis \\
\hline 11 & $\mathrm{AH}_{1}$ & 2 & 21 & 23 & 21 & 23 & 0 & 0 & Kritis \\
\hline 12 & $\mathrm{AH}_{2}$ & 2 & 23 & 25 & 27 & 29 & 4 & 0 & Non Kritis \\
\hline 13 & $\mathrm{AI}_{1}$ & 2 & 23 & 25 & 23 & 25 & 0 & 0 & Kritis \\
\hline 14 & $\mathrm{AI}_{2}$ & 1 & 25 & 26 & 28 & 29 & 3 & 0 & Non Kritis \\
\hline 15 & $\mathrm{AJ}_{1}$ & 2 & 25 & 27 & 25 & 27 & 0 & 0 & Kritis \\
\hline 16 & $\mathrm{AJ}_{2}$ & 2 & 27 & 29 & 27 & 29 & 0 & 0 & Kritis \\
\hline 17 & $\mathrm{AN}_{1}$ & 2 & 29 & 31 & 29 & 31 & 0 & 0 & Kritis \\
\hline 18 & $\mathrm{AN}_{2}$ & 2 & 31 & 33 & 32 & 34 & 1 & 0 & Non Kritis \\
\hline 19 & $\mathrm{AP}_{1}$ & 2 & 31 & 33 & 31 & 33 & 0 & 0 & Kritis \\
\hline 20 & $\mathrm{AP}_{2}$ & 1 & 33 & 34 & 33 & 34 & 0 & 0 & Kritis \\
\hline 21 & $\mathrm{AQ}_{1}$ & 2 & 34 & 36 & 34 & 36 & 0 & 0 & Kritis \\
\hline 22 & $\mathrm{AQ}_{2}$ & 2 & 36 & 38 & 37 & 39 & 1 & 0 & Non Kritis \\
\hline 23 & $\mathrm{AS}_{1}$ & 2 & 36 & 38 & 36 & 38 & 0 & 0 & Kritis \\
\hline 24 & $\mathrm{AS}_{2}$ & 1 & 38 & 39 & 38 & 39 & 0 & 0 & Kritis \\
\hline 25 & $\mathrm{BI}_{1}$ & 2 & 39 & 41 & 39 & 41 & 0 & 0 & Kritis \\
\hline 26 & $\mathrm{BI}_{2}$ & 2 & 41 & 43 & 42 & 44 & 1 & 0 & Non Kritis \\
\hline 27 & $\mathrm{BI}_{3}$ & 1 & 43 & 44 & 44 & 45 & 1 & 0 & Non Kritis \\
\hline 28 & $\mathrm{BK}_{1}$ & 2 & 41 & 43 & 41 & 43 & 0 & 0 & Kritis \\
\hline 29 & $\mathrm{BK}_{2}$ & 2 & 43 & 45 & 43 & 45 & 0 & 0 & Kritis \\
\hline 30 & $\mathrm{BL}_{1}$ & 2 & 45 & 47 & 45 & 47 & 0 & 0 & Kritis \\
\hline 31 & $\mathrm{BL}_{2}$ & 2 & 47 & 49 & 48 & 50 & 1 & 0 & Non Kritis \\
\hline 32 & $\mathrm{BL}_{3}$ & 1 & 49 & 50 & 50 & 51 & 1 & 0 & Non Kritis \\
\hline 33 & $\mathrm{BN}_{1}$ & 2 & 47 & 49 & 47 & 49 & 0 & 0 & Kritis \\
\hline 34 & $\mathrm{BN}_{2}$ & 2 & 49 & 51 & 49 & 51 & 0 & 0 & Kritis \\
\hline 35 & $\mathrm{CM}_{1}$ & 2 & 51 & 53 & 51 & 53 & 0 & 0 & Kritis \\
\hline 36 & $\mathrm{CM}_{2}$ & 1 & 53 & 54 & 56 & 57 & 3 & 0 & Non Kritis \\
\hline 37 & $\mathrm{CO}_{1}$ & 2 & 53 & 55 & 53 & 55 & 0 & 0 & Kritis \\
\hline
\end{tabular}

\begin{tabular}{|c|c|c|c|c|c|c|c|c|c|}
\hline 38 & $\mathrm{CO}_{2}$ & 2 & 55 & 57 & 55 & 57 & 0 & 0 & Kritis \\
\hline 39 & $\mathrm{CO}_{3}$ & 2 & 57 & 59 & 57 & 59 & 0 & 0 & Kritis \\
\hline 40 & $\mathrm{AW}_{1}$ & 2 & 59 & 61 & 59 & 61 & 0 & 0 & Kritis \\
\hline 41 & $\mathrm{AW}_{2}$ & 2 & 61 & 63 & 62 & 64 & 1 & 0 & Non Kritis \\
\hline 42 & $\mathrm{AY}_{1}$ & 2 & 61 & 63 & 61 & 63 & 0 & 0 & Kritis \\
\hline 43 & $\mathrm{AY}_{2}$ & 1 & 63 & 64 & 63 & 64 & 0 & 0 & Kritis \\
\hline 44 & $\mathrm{AZ}_{1}$ & 2 & 64 & 66 & 64 & 66 & 0 & 0 & Kritis \\
\hline 45 & $\mathrm{AZ}_{2}$ & 2 & 66 & 68 & 67 & 69 & 1 & 0 & Non Kritis \\
\hline 46 & $\mathrm{BB}_{1}$ & 2 & 66 & 68 & 66 & 68 & 0 & 0 & Kritis \\
\hline 47 & $\mathrm{BB}_{2}$ & 1 & 68 & 69 & 68 & 69 & 0 & 0 & Kritis \\
\hline 48 & $\mathrm{BC}_{1}$ & 2 & 69 & 71 & 69 & 71 & 0 & 0 & Kritis \\
\hline 49 & $\mathrm{BC}_{2}$ & 2 & 71 & 73 & 73 & 75 & 2 & 0 & Non Kritis \\
\hline 50 & $\mathrm{BE}_{1}$ & 2 & 71 & 73 & 71 & 73 & 0 & 0 & Kritis \\
\hline 51 & $\mathrm{BE}_{2}$ & 2 & 73 & 75 & 73 & 75 & 0 & 0 & Kritis \\
\hline 52 & $\mathrm{BE}_{3}$ & 1 & 75 & 76 & 75 & 76 & 0 & 0 & Kritis \\
\hline 53 & $\mathrm{BF}_{1}$ & 2 & 73 & 75 & 73 & 75 & 0 & 0 & Kritis \\
\hline 54 & $\mathrm{BF}_{2}$ & 1 & 75 & 76 & 75 & 76 & 0 & 0 & Kritis \\
\hline 55 & $\mathrm{BH}_{2}$ & 2 & 76 & 78 & 76 & 78 & 0 & 0 & Kritis \\
\hline 56 & $\mathrm{CD}_{1}$ & 2 & 78 & 80 & 78 & 80 & 0 & 0 & Kritis \\
\hline 57 & $\mathrm{CD}_{2}$ & 2 & 80 & 82 & 83 & 85 & 3 & 0 & Non Kritis \\
\hline 58 & $\mathrm{CD}_{3}$ & 1 & 82 & 83 & 85 & 86 & 3 & 0 & Non Kritis \\
\hline 59 & $\mathrm{CF}_{1}$ & 2 & 80 & 82 & 80 & 82 & 0 & 0 & Kritis \\
\hline 60 & $\mathrm{CF}_{2}$ & 2 & 82 & 84 & 84 & 86 & 2 & 0 & Non Kritis \\
\hline 61 & $\mathrm{CG}_{1}$ & 2 & 82 & 84 & 82 & 84 & 0 & 0 & Kritis \\
\hline 62 & $\mathrm{CG}_{2}$ & 2 & 84 & 86 & 84 & 86 & 0 & 0 & Kritis \\
\hline 63 & $\mathrm{CG}_{3}$ & 1 & 86 & 87 & 86 & 87 & 0 & 0 & Kritis \\
\hline 64 & $\mathrm{CI}_{2}$ & 3 & 87 & 90 & 87 & 90 & 0 & 0 & Kritis \\
\hline
\end{tabular}

\section{HASIL DAN PEMBAHASAN}

Perencanaan merupakan bagian terpenting untuk mencapai keberhasilan proyek konstruksi. Pengaruh perencanaan terhadap proyek konstruksi akan berdampak pada pendapatan dalam proyek itu sendiri. Salah satu bentuk dari perencanaan suatu proyek adalah penjadwalan proyek. Penjadwalan proyek merupakan salah satu elemen hasil perencanaan, yang dapat memberikan informasi tentang jadwal rencana dan kemajuan proyek dalam hal kinerja sumber daya berupa biaya, tenaga kerja, peralatan dan material serta rencana durasi proyek dengan progress waktu untuk penyelesaian proyek.

Mempercepat jadwal dengan mengerjakan bagian-bagian lingkup proyek secara tumpang tindih dan merupakan salah satu manfaat yang potensial dapat di raih dari penggunaan Konsultan Manajemen Proyek.. Maksudnya agar kegiatan-kegiatan lain dapat dilaksanakan bertingkatan dengan bagian-bagian yang lebih kecil tadi. Menggunakan Metode Overlap atau Fast Tracking Method karena jika dibandikan metode lain, metode ini dinilai lebih efektif dan efisien untuk melakukan percepatan waktu pelaksanaan proyek.

Pembangunan Student Center Fakultas Kedokteran Universitas Hasanuddin direncanakan dengan menggunakan Metode Overlap atau Fast Tracking Method, mempercepat jadwal dengan mengerjakan bagianbagian lingkup proyek secara tumpang tindih. Dari hasil penelitian didapat durasi normal dari perencanaan Proyek Pembangunan Student Center Fakultas Kedokteran Universitas Hasanuddin adalah 118 Hari. Berdasarkan penelitian menggunakan Metode Overlap atau Fast Tracking Method, mempercepat jadwal dengan mengerjakan bagian-bagian lingkup proyek secara tumpang tindih memiliki waktu proyek selama 90 hari, dengan efisiensi waktu 28 Hari

Dari hasil penelitian ini dapat dilihat bahwa menggunakan Metode Overlap atau Fast Tracking Method, efisien dibandingkan dari perencanaan sebelumnya. 


\section{PENUTUP}

\subsection{Kesimpulan}

Dari hasil analisis data dan pembahasan Pembangunan Student Center Fakultas Kedokteran Universitas Hasanuddin direncanakan dengan menggunakan Metode Overlap atau Fast Tracking Method, maka penulis dapat memberikan kesimpulan yaitu perpendekan Jalur Kritis dihitung menggunakan Metode overlap atau fast tracking method yaitu 90 Hari lebih efisien dibandingkan dari perencanaan lama yaitu durasi 118 hari. Metode Overlap atau Fast Tracking Method dinilai lebih efektif dan efisien untuk melakukan percepatan waktu pelaksanaan proyek, karena mempercepat jadwal dengan mengerjakan bagian-bagian lingkup proyek secara tumpang tindih. Maksudnya agar kegiatan-kegiatan lain dapat dilaksanakan bertingkatan dengan bagianbagian yang lebih kecil.

\subsection{Saran}

Setelah menggunakan Metode Overlap atau Fast Tracking Method, maka penulis dapat memberikan saran yakni ketelitian dalam penginputan dan pengolahan data dalam perhitungan sangat diperlukan agar output yang diperoleh sesuai dengan keadaan sebenarnya. Untuk memperoleh hasil yang baik dan akurat dalam perhitungan sebaiknya menggunakan alat bantu program komputer.

\section{DAFTAR PUSTAKA}

Anderson David R, 1996. Manajemen Sains: Pendekatan Kuintatif Untuk Pemgambilan Keputusan Manajemen Jilid 1, Erlangga, Jakarta.

Arianie GP. Puspitasari NB. (2017). Perencanaan Manajemen proyek dalam Meningkatkan Efisiensi dan Efektifitas Sumber Daya perusahaan (Studi kasus: Qiscus Pte Ltd). Jurnal Teknik Industri 12(3)

Ismael I,. (2013). Keterlambatan Proyek Konstruksi Gedung Faktor Penyebab dan Tindakan pencegahannya.Jurnal Momentum Teknik Geodesi Institut Teknologi Padang 14(1)

Jusmidah. (2016). Analisis Produktivitas tenaga Kerja pada Proyek Pekerjaan jembatan Ammasangan. PENA TEKNIK: Jurnal Ilmiah Ilmu-ilmu Teknik 1(1), 47 - 54.

Sudarsana DK. (2018). Pengendalian Biaya dan Jadual Terpadu pada proyek Konstruksi. Jurnal Ilmiah teknik Sipil 12(2).

Sulistiono, Waluyo. (2016). Tinjauan Manajemen investasi pada proyek PLTM Siteba IV Kabupaten Luwu. PENA TEKNIK: Jurnal Ilmiah Ilmu-ilmu Teknik 1(1), 39- 46

Tanjung, Masyur. (2017). Fungsi organisasi Dalam Manajemen Proyek. Jurnal Mantik Penusa 1(1) 